\title{
The Impact Study of Houseplants in Purification of Environment Using Wireless Sensor Network
}

\author{
Kalpana A. Kulkarni, Madhukar S. Zambare \\ Department of Electronic Science, Fergusson College, Pune, India \\ Email: kalpana.kulkarni@fergusson.edu,drmsz29@gmail.com
}

How to cite this paper: Kulkarni, K.A. and Zambare, M.S. (2018) The Impact Study of Houseplants in Purification of Environment Using Wireless Sensor Network. Wireless Sensor Network, 10, 59-69. https://doi.org/10.4236/wsn.2018.103003

Received: January 29, 2018

Accepted: March 28, 2018

Published: March 31, 2018

Copyright $\odot 2018$ by authors and Scientific Research Publishing Inc. This work is licensed under the Creative Commons Attribution International License (CC BY 4.0).

http://creativecommons.org/licenses/by/4.0/

\begin{abstract}
Emergence of environmental issues such as air pollution has greatly required the need for robust, cheap, operationally adaptable, and smart monitoring systems. The proposed work describes a study of how the household plants are helpful in purifying the environment. Air pollution monitoring system has been developed using Wireless Sensor Network (WSN). Sensor nodes and embedded system are used for monitoring air quality. The monitoring system consists of sensor nodes, base station and PC for data processing, storage, and presentation. Once data is collected at PC, it is then compiled and presented on web server.
\end{abstract}

\section{Keywords}

Houseplants, Sensors, Wireless Sensor Network

\section{Introduction}

Air pollution is a major environmental concern in most major cities. As society grew more civilized and industrialized, contamination of the air increased a lot and contributed to the pollution of the atmosphere. Thousands of activities contribute to the overload of air pollution. Volcanoes, decaying plants and animals and dust are natural sources of pollution [1]. Thus air quality has a huge impact on different aspects of life quality and therefore air quality monitoring is required.

Poor indoor air quality has been linked to many health related issues especially in children. Allergy and asthma are to be considered as the most common chronic disease in urban dwelling children [2]. Indoor air filtrations are required to improve respiratory health. Air cleaners with different given filters have been shown to improve symptoms of asthma type of disease.

However, filtration systems and air purifiers do not reduce levels of all indoor 
air pollutants, and some types can actually aggravate the problem. For example, one study showed that some air purifiers raise indoor concentrations of ozone above safety levels. In addition, air filtration could be the use of houseplants. Trees and other vegetation absorb pollutants and play large role in cleansing the atmosphere. Trees are an important, cost effective solution to reducing pollution and improving air quality [3].

In addition to basic photosynthesis that removes carbon dioxide and returns oxygen to air, plants can remove toxicants/impurities from air, soil and water in at least two ways. First, they can metabolize some toxic chemicals, releasing harmless by-products; secondly they can incorporate toxicants, such as heavy metals into plant tissues, thus sequestering them. Trees and plants provide many benefits, including the ability to condition the atmospheric environment. In addition to regulating temperature, humidity and air movement, trees interact with air pollutants in various ways. Some trees are injured by gases and particles in the air, while others absorb and use contaminants without apparent harm.

Trees also reduce pollution by actively removing it from the atmosphere. Leaf stomata, the pores on the leaf surface, takes in polluting gases which are the absorbed by water inside the leaf. Many researchers already studied that trees remove carbon monoxide $(\mathrm{CO})$, sulfer dioxide $\left(\mathrm{SO}_{2}\right)$, nitrogen dioxide $\left(\mathrm{NO}_{2}\right)$ and ozon from air. In this work, we have tried to understand the complex interactions between plants and the atmosphere. In closed controlled environment, we were monitoring the concentration level of oxygen $\left(\mathrm{O}_{2}\right)$ and carbon dioxide $\left(\mathrm{CO}_{2}\right)$, light, temperature and humidity.

Trees may absorb some pollutants in the natural life processes common to all plants. In an exchange of gases, plants take in carbon dioxide, convert it to food and release oxygen. This exchange occurs through stomata or pores on the leaf's surface. During normal opening of theses pores, other elements may also enter. These include pollutants such as chlorine, sulfur dioxide and fluorides. The plant uses some of these materials as food, and releases others into the air or soil. In this way, plants receive nutrition and possibly help to purify the air as well.

The overall pattern of leaves-their number, arrangement, and density, as well as the closeness and configuration of trees, may affect trees ability to reduce the level of air pollution. A sparse canopy, for instance, has less potential for cleansing than a big, thick canopy [4]. For studying some houseplants that have the ability to naturally improve the air quality of our home, all of these indoor houseplants were analyzed. They found that each had a unique way to naturally cleanse the air of toxins that have a negative effect on our health.

\section{Selection of Plants}

In proposed work the plants which are used are: Tulsi plant is selected as a main plant for the observations as shown in Figure 1 and other plants as shown in Figure 2.

a) Tulsi (Ocimum sanctum or Holy basi): Tulsi gives out oxygen for 20 hours a 
day along with the formation of nascent oxygen. It absorbs harmful gases like, carbon dioxide, carbon monoxide and sulphur dioxide from the environment.

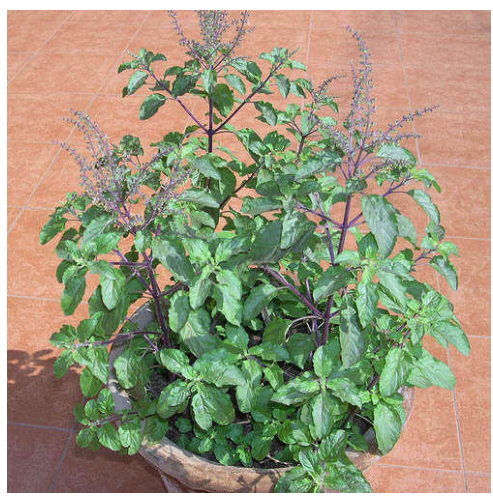

Figure 1. Tulsi plant.

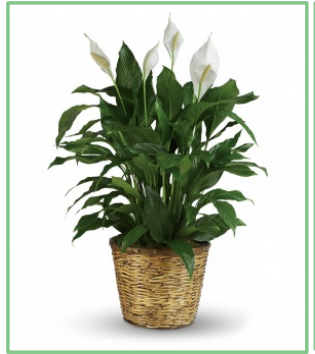

(a)

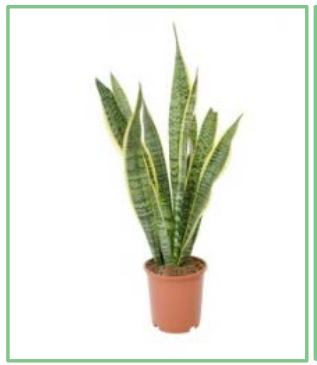

(d)

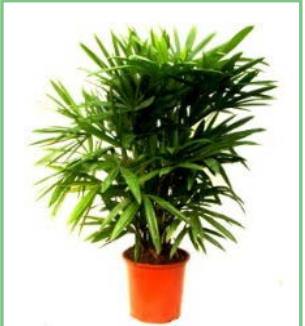

(g)

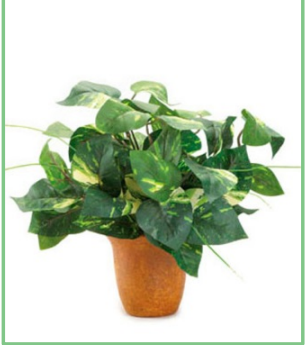

(b)

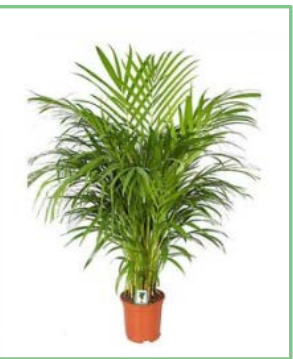

(e)

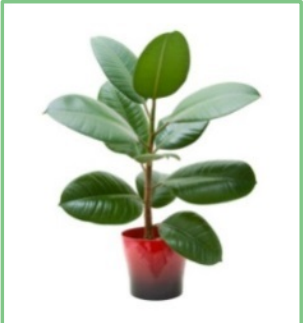

(h)

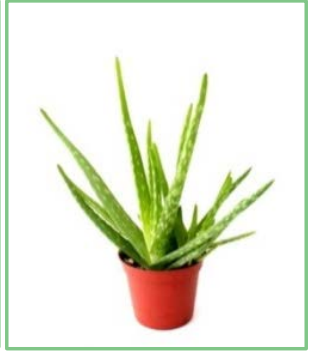

(c)

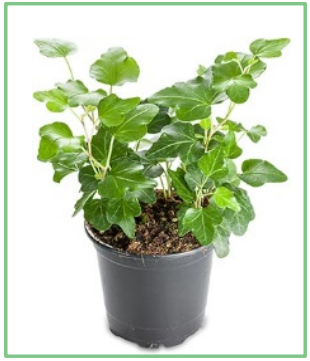

(f)

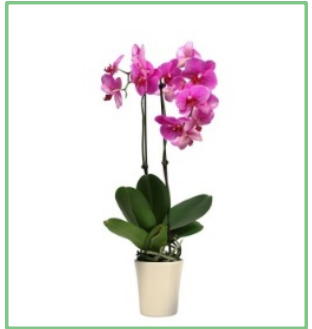

(i)

Figure 2. Plants used for experimentation: (a) Peace Lily (Spathiphyllum); (b) Devil's Ivy (Epipremnum aureum); (c) Aloe Vera; (d) Snake Plant (Sansevieria trifasciata); (e) Areca Palm (Dypsis lutescens); (f) English Ivy (Hedera helix); (g) Lady Palm (Rhapis); (h) Rubber Plant (Ficus elastic); (i) Orchid (Orchidaceae). 
b) Peace Lily (Spathiphyllum): It gives oxygen at less light also and reduces the carbon dioxide level and purifies the air. They require very little light or water to remain healthy. NASA analysis of indoor houseplants revealed that the Piece Lily was the most efficient at removing airborne Volatile Organic Compound, including formaldehyde, trichloroethylene and benzene. Simply put in dark corner, give it water once a week and this little plant will help purify the air around that general area.

c) Devil's Ivy (Epipremnum aureum): With evergreen vines and small green heart shaped leaves is quite efficient at cleansing the air pollutants such as benzene, trichloroethylene, xylene, formaldehyde and keeping air fresh with giving oxygen.

d) Snake Plant (Sansevieria trifasciata): Often referred to as Snake plant or Mother-in-Law Tongue. This evergreen perennial plant is another houseplant that is known to improve indoor air quality. It is one of the best houseplants for absorbing airborne toxins, including formaldehyde, nitrogen oxide, benzene, xylene and trichloroethylene. It converts a lot of $\mathrm{CO}_{2}$ to $\mathrm{O}_{2}$ at night, making it ideal to have several in room. 6-8 waist high plants are needed per person to survive if there is no air flow. Since they don't need a lot of light or water to survive, snake plant is easy choice for any corner of your home.

e) Aloe Vera: Aloe Vera emits oxygen at night and increases the longevity of your life. It is almost a "no-maintenance" plant and caters to a lot of beauty benefits too.

f) Areca Palm: This plant removes xylene and toluene from the air, but also happens to convert a lot of $\mathrm{CO}_{2}$ to $\mathrm{O}_{2}$ during the daytime and continuously remove chemical toxins from the air. Having four (shoulder high plants) of these per person in your household provides enough oxygen to survive on during daylight hours! They need to have dust and grime wiped off of their leaves once a week.

g) Orchids: Beautiful and beneficial, orchids are a perfect choice to be settled in the corner of room. Apart from emitting oxygen during the nighttime, Orchids also banish xylene-pollutant found in paints, and fills the room with fresh air to breathe.

h) English Ivy (Hedera helix): Popular houseplant that helps filter airborne toxins inside your home. English Ivy is effective at cleansing benzene, formaldehyde, xylene and toluene from the air. It also helps to reduce mold.

i) Lady Palm: Lady Palm can be kept in dry or humid climates and is fiercely resistant to most types of plant insects.

j) Rubber Plant: Rubber plants excel at removing chemical toxins from indoor air, requiring less light than many other plants and outperforming all other ficuses.

\section{Selection of Sensors}

Senors Used to sense Oxygen concentration and Carbon Dioxide Concentration. 
a) TGS 4161-Carbon Dioxide Sensor: Solid electrolyte $\mathrm{CO}_{2}$ sensor as shown in Figure 3. Range of 350 - 10,000 ppm of carbon dioxide can be detected. $\mathrm{CO}_{2}$ sensitive element consists of a solid electrolyte formed between two electrodes, together with a printed heater $\left(\mathrm{RuO}_{2}\right)$ substrate. Monitoring the change in electromotive force (EMF) generated between the two electrodes, it is possible to measure $\mathrm{CO}_{2}$ concentration [5].

b) KE-25-Oxygen Sensor: Oxygen Sensor KE-Series is a unique galvanic cell type oxygen sensor show in Figure 4. Provides a linear output voltage signal relative to percent oxygen present, No external power supply required for sensor operation. Virtually no influence from $\mathrm{CO}_{2}, \mathrm{CO}, \mathrm{H}_{2} \mathrm{~S}, \mathrm{NOx}, \mathrm{H}_{2}$. No external power supply required for sensor operation. No warm-up time is required [5].

c) DHT11 Sensor is used for Temperature and Humidity measurement.

\section{Wireless Sensor Network}

WSN consists of different nodes. It consists of Gateway module, Radio Module and Sensors. These nodes are connected in different ways. Node connected to PC is Sink node and configured as Base station and node to which sensors are connected are Sourse nodes. Each node is programmed using Eclips IDE. Base station collects the data from different sourse nodes and then it sends the data to the cloud through wireless network.

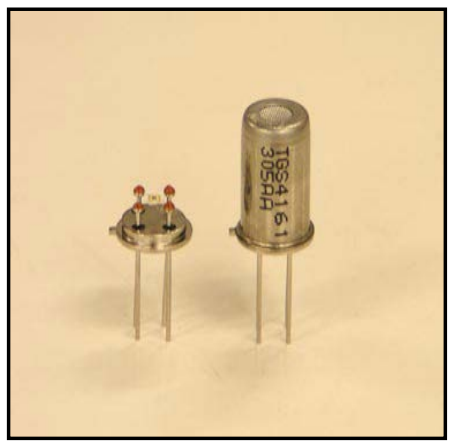

Figure 3. $\mathrm{CO}_{2}$ Sensor.

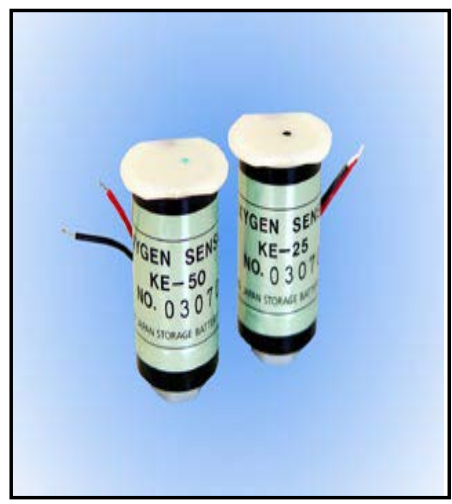

Figure 4. $\mathrm{O}_{2}$ Sensor. 
Communication within the network is implemented using the IEEE 802.15.4 standard [6], while data are transmitted over the ZigBee protocol stack [7] [8]. Among the known data wireless transmission standards, such as Bluetooth, Wi$\mathrm{Fi}$, etc., we have found ZigBee the most acceptable in terms of the trade-off between bandwidth and power consumption, to ensure long autonomous battery operation of the device. In addition, the modems which use the ZigBee standard have the option to self-organize the whole sensor network [9] [10] [11] [12].

An Environmental Sensor Network comprises an array of sensor nodes and a communications system which allows their data to reach a server, Figure 5 . The sensor nodes gather data autonomously and a data network is usually used to pass data to one or more base stations, which forward it to a Sensor Network Server (SNS). Some systems send commands to the nodes in order to fetch the data, while others allow the nodes to send data out autonomously. Experimentations were done in closed controlled environmental chamber. Complete experimental setup is shown in Figure 6. Once the data has been received in base station from different sensor nodes and then data is stored in data base. All this can be visualized in graphical user interface developed (GUI). Through this GUI developed we can program the sensor and base node depending upon the network topology required. Different windows of GUI developed are shown in Figures 7-9.

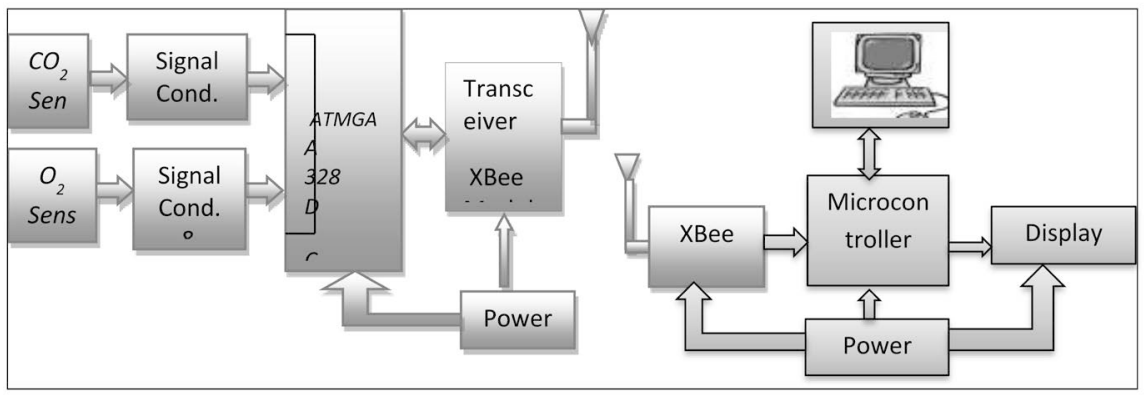

Figure 5. Block diagram of transmitter and receiver section.

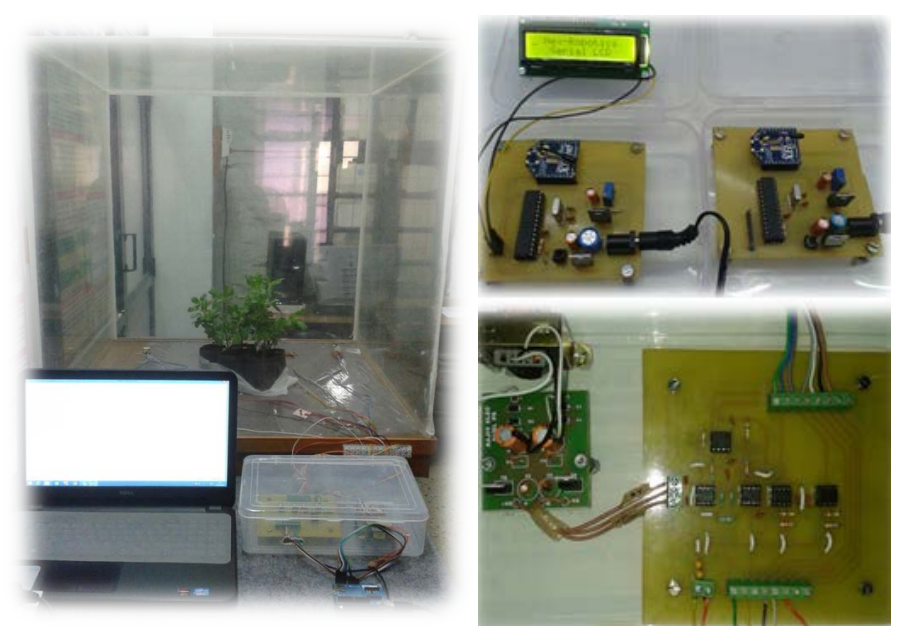

Figure 6. Experimental setup and electronic circuitary. 


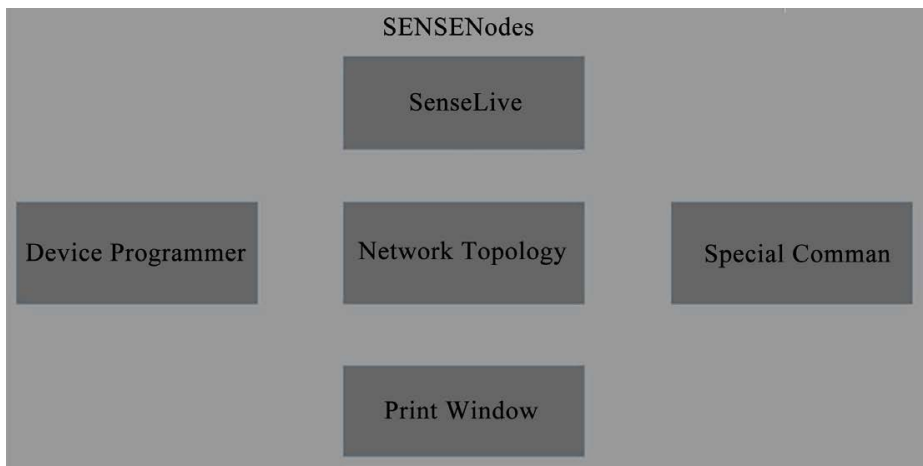

Figure 7. Main GUI Window.

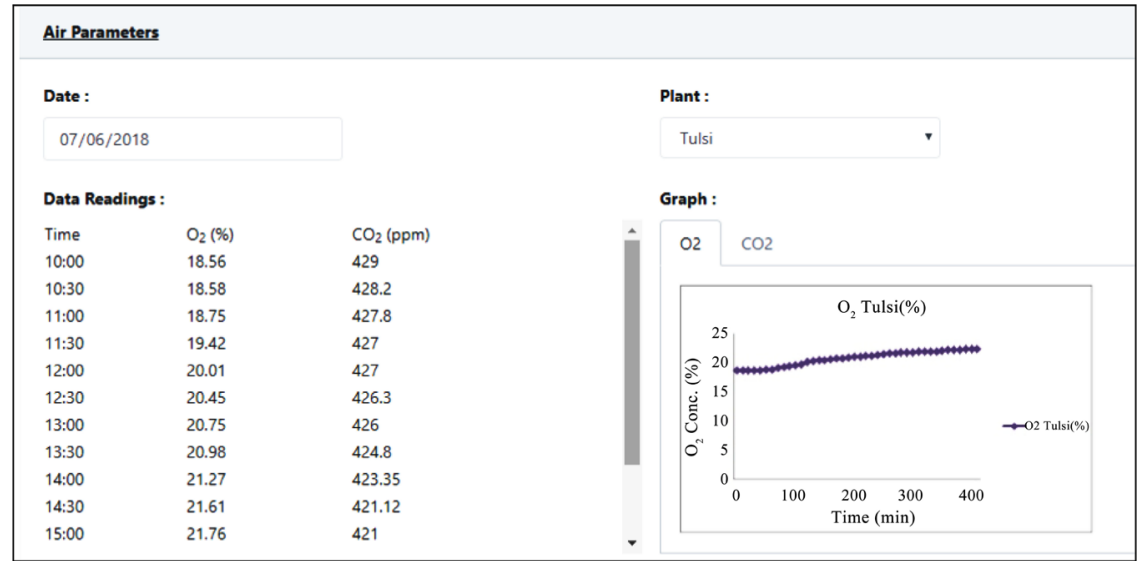

Figure 8. GUI: Programming Window.

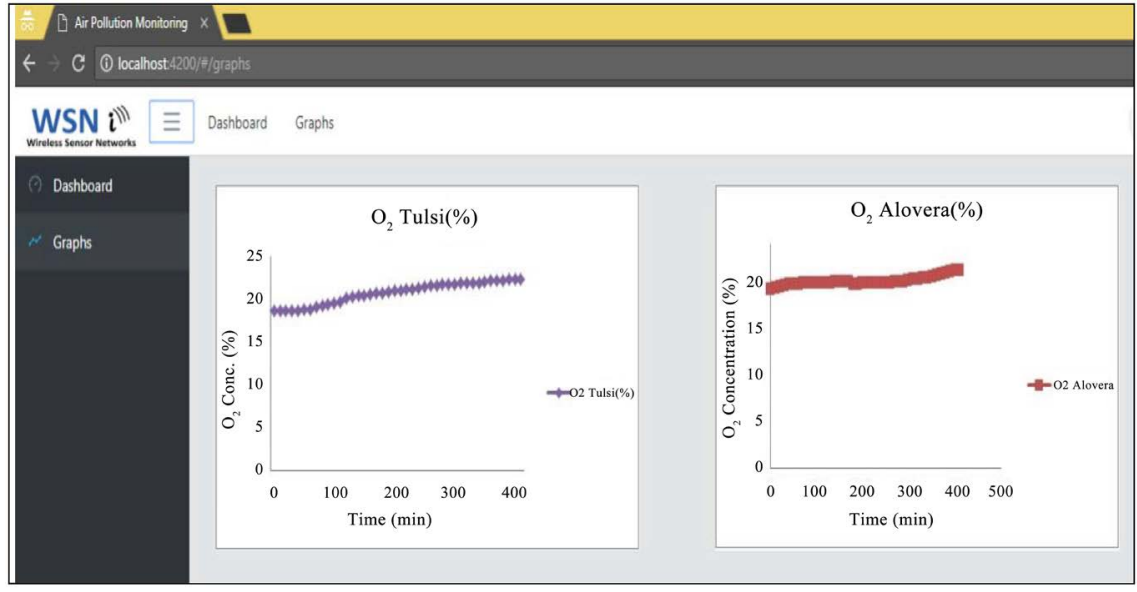

Figure 9. GUI: Data Collection Window.

\section{Observations and Results}

$\mathrm{O}_{2}$ Concentration and $\mathrm{CO}_{2}$ Concentration due to different plants are sensed by sensors TGS 4161 and KE 25 and these data has been monitored using system developed. The actual reading when taken in the closed environmental chamber is shown in Table 1. From these reading ratio of absorption of $\mathrm{CO}_{2}$ to release of $\mathrm{O}_{2}$ is calculated as shown in Table 2. 
Table 1. $\mathrm{O}_{2}$ and $\mathrm{CO}_{2}$ concentratin for different plants.

\begin{tabular}{ccccc}
\hline \multirow{2}{*}{ Plant Name } & \multicolumn{2}{c}{$\mathrm{O}_{2}$ Concentration (\%) } & \multicolumn{2}{c}{$\mathrm{CO}_{2}$ Concentration (ppm) } \\
\cline { 2 - 5 } & $\mathrm{T}=0 \mathrm{sec}$ & $\mathrm{T}=400 \mathrm{~min}$ & $\mathrm{~T}=0 \mathrm{~min}$ & $\mathrm{~T}=400 \mathrm{~min}$ \\
\hline Tulasi & 18.56 & 22.3 & 429 & 410 \\
Aloevera & 19.12 & 21.07 & 428 & 418 \\
Peace Lily & 19.00 & 20.62 & 428 & 420 \\
Devils Ivy & 19.00 & 21.00 & 428 & 420 \\
Snake Plant & 19.00 & 21.00 & 429 & 419 \\
Orchids & 19.00 & 21.1 & 429 & 421 \\
Lady Palm & 19.00 & 21.32 & 427 & 419 \\
Rubber Plant & 19.00 & 21.24 & 426 & 418 \\
English Ivy & 19.00 & 21.18 & 427 & 419 \\
Areca Palm & 18.56 & 21.33 & 428 & 419 \\
\hline
\end{tabular}

Table 2. Absorption of $\mathrm{CO}_{2}$ and emission of $\mathrm{O}_{2}$ of plants for given fixed time period.

\begin{tabular}{cc}
\hline Plant & Ratio \\
\hline Tulsi & $4: 1$ \\
Aloe Vera & $5: 1$ \\
Peace Lily & $4: 1$ \\
Devils Ivy & $4: 1$ \\
Snake Plant & $5: 1$ \\
Orchids & $4: 1$ \\
Lady Palm & $3: 1$ \\
Rubber Plant & $3: 1$ \\
English Ivy & $3: 1$ \\
Areca Palm & $3: 1$ \\
\hline
\end{tabular}

Observations show that the concentration of $\mathrm{CO}_{2}$ decreases due to absorption by plants and $\mathrm{O}_{2}$ concentration increases. Thus these household plants in some way reduce the pollution by increasing the oxygen content in the atmosphere. For different plants, what we got the results are shown graphically in Figures 10-13. Sensor data is transmitted by sensor node to the receiver base node. To validate the Transmitter and Received data are same or not, transmitter data has been displayed on LED display for visualization as shown in Figure 14.

\section{Conclusions}

Wireless air pollution monitoring system has been developed and tested in different tree cover area and non-tree cover area. The impact of tree cover area/non tree cover area on air pollution is co-related with due consideration of $\mathrm{CO}_{2}$ depletion and $\mathrm{O}_{2}$ emission concentration. Other parameters like temperature and 


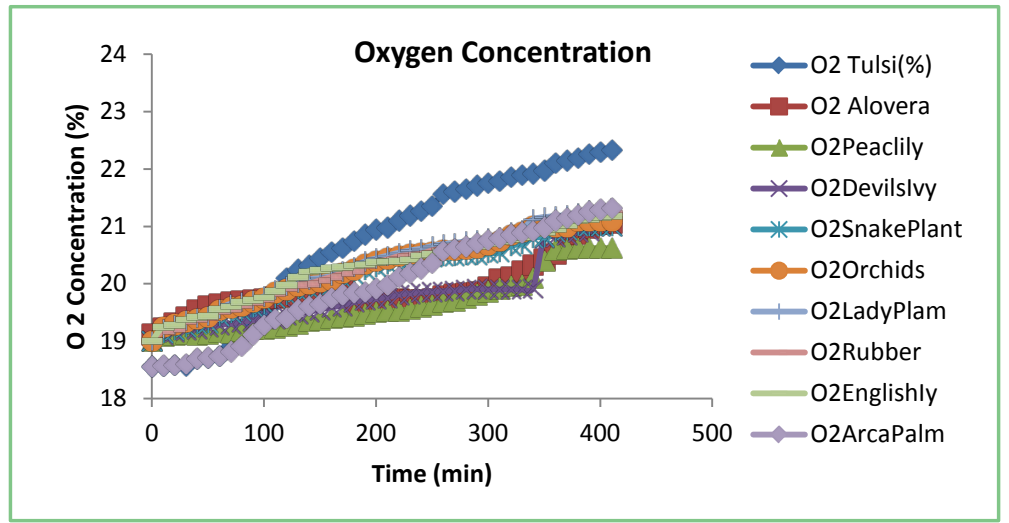

Figure 10. Oxygen concentration (\%) V time (min).

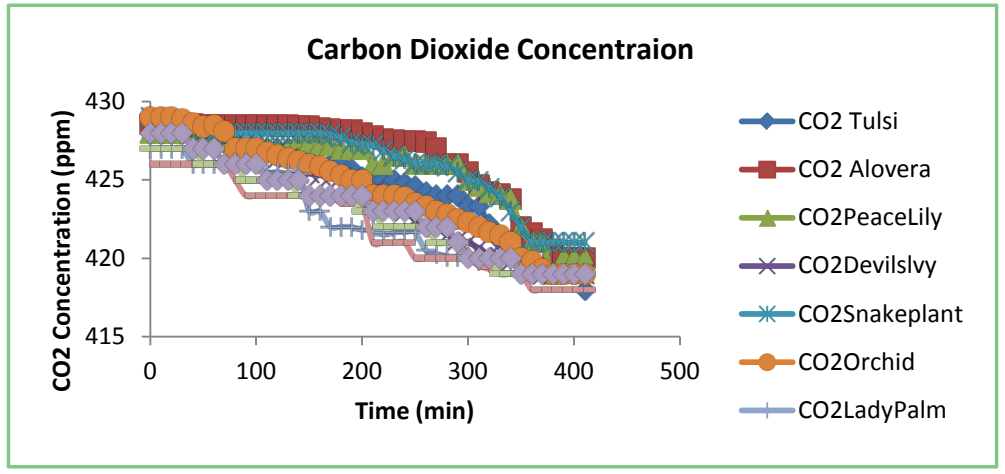

Figure 11. Carbon dioxide concentration (ppm) V time (min).

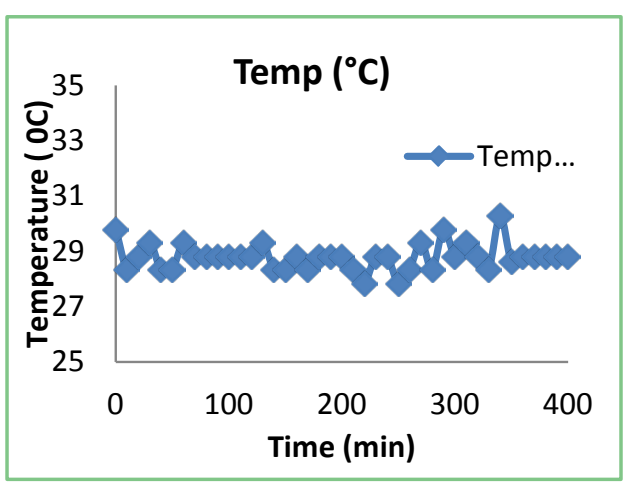

Figure 12. Temperature (0C) V time (min).

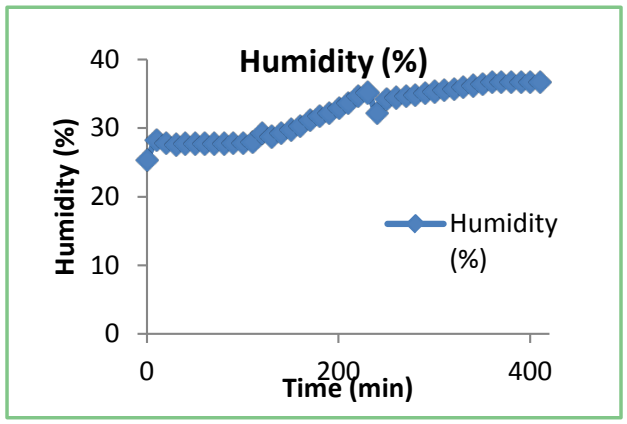

Figure 13. Humidity (\%) V time (min). 


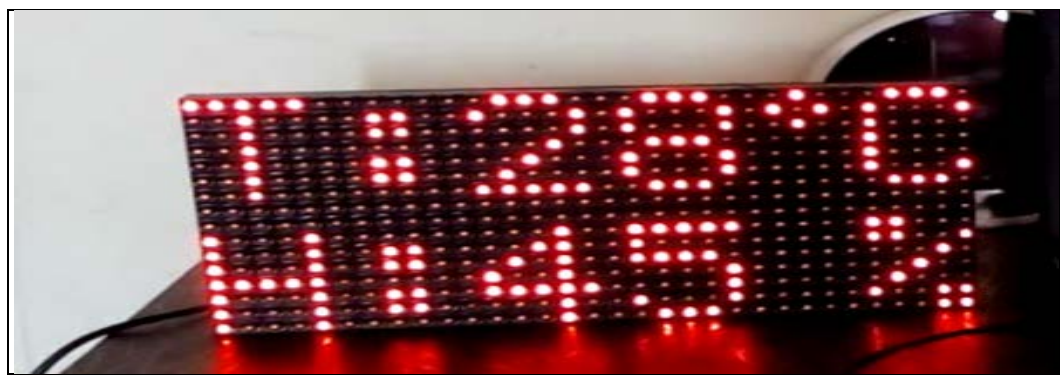

Figure 14. Parameters on LED Display.

relative humidity also monitored. Sensor nodes have been checked at different locations. The collected data represented using GUI.

The importance of real-time wireless air pollution monitoring system is investigated considering the vital technical and economic issues for vast area deployment. Experimentation has been carried out using the developed wireless air pollution monitoring system under different environmental conditions so that the system collects reliable source of real time data.

For environmental conservation, a new concept of performing high-speed data acquisition based on remote sensors, and an accurate transmission and processing of the meteorological parameters towards obtaining useful data for the users were developed in connection with the center services. New methods of interconnecting hardware and dedicated software support were successfully implemented in order to increase the quality and precision of measurements. At the same time, the Web concept itself is changing the way the measurements are made available and the results are distributed/communicated. WSN can be deployed in several cities to monitor the concentration of various gases.

\section{Acknowledgements}

Authors express sincere thanks to Dr. R. G. Pardeshi, Principal, Fergusson College and Dr. N. M. Kulkarni, Head, Department of Electronic Science, Fergusson College, Pune for permitting us to carry out research work in the institute and providing the necessary facilities. Authors also acknowledge Dr. A. D. Shaligram, Head, Department of Electronic Science, Savitribai Phule Pune University, Pune for his critical remarks and discussion about the theoretical aspects.

\section{References}

[1] Kuklinska, K., Jacek, W. and Namiesnik, Atmospheric Pollution Research. (2015) Air Quality Policy in the U.S. and the EU-A Review. Critical Literature Review, 6, 129-137. https://doi.org/10.5094/APR.2015.015

[2] (2014) Air Quality Index (AQI) - Guide to Air Quality and Your Health. http://www.airnow.gov/index.cfm?action\%20=aqibasics.aqi

[3] Review on Urban Vegetation and Particle Air Pollution Deposition and Dispersion, Sara Janhäll, Atmospheric Environment 105 (2015) http://www.elsevier.com/locate/atmosenv

[4] Nowak, D.J., Crane, D.E. and Stevens, J.C. (2006) Air Pollution Removal by Urban 
Trees and Shrubs in the United States. Urban for. Urban Green, 4, 115-123. https://doi.org/10.1016/j.ufug.2006.01.007

[5] Figaro's Engineering Inc. Technical Information for TGS 4161, KE-25.

[6] Baronti, P., Pillai, P., Chook, V.W.C., Chessa, S., Gotta, A. and Hu, Y.F. (2007) Wireless Sensor Networks: A Survey on the State of the Art and the 802.15.4 and ZigBee Standards. Computer and Communications, 30, 1655-1695. https://doi.org/10.1016/j.comcom.2006.12.020

[7] Kulartna, N. and Sudantha, B.H. An Environmental Air Pollution Monitoring System Based on the IEEE 1451 Standard for Low Cost Requirements. IEEE Sensors.

[8] IEEE Standards Association (2010) http://standard.ieee.org/about/get/802/802.15.htm

[9] Zigbee Specification (2010) http://www.eas.uccs.edu/ cwang/ECE5452_SOC/SOC_Zigbee.pdf

[10] Pardo, A., Caara, L. and Care, J. (2009) Gas Measurement System Based on IEEE standard. Sensors and Actuators B, 16, 11-16.

[11] IEEE, Wireless Medium Access Control (MAC) and Physical Layer (PHY) Specifications for Wireless Personal Area Networks (WPANs). The Institute of Electrical and Electronics Engineers Inc., New York, NY, USA.

[12] Chou, J. (1999) Hazardous Gas Monitors: A Practical Guide to Selection, Operation, and Applications. McGraw-Hill, New York. 